\title{
Psicanálise em movimento: a mente transiente do analista ${ }^{1}$
}

\author{
Carmen C. Mion ${ }^{2}$
}

“O pó com vento é vida. O pó sem vento é morte."

Ariano Suassuna

Deverei hoje tecer um comentário inspirado pelas interessantes apresentações de dois colegas experientes, Marcio Giovannetti e Mariano Horenstein, a respeito do tema do simpósio de hoje, "O analista desconcertado: mal-estar e clínica". Dentre os diferentes caminhos possíveis para tanto, resolvi abordar dois: um convergente com os autores, em que pese os diferentes referenciais teóricos, e um outro que, embora relacionado ao primeiro, introduz um vértice divergente dos autores.

1. O analista desconcertado - Márcio afirma que "falar do analista desconcertado é falar e pensar o analista em seu trabalho diário às voltas com a escuta da palavra, ou como escreveu Green, com o discurso vivo do paciente". Por outro lado, Mariano, a partir do seu modelo do analista como um detetive selvagem, apresentado a partir do lugar do "estrangeiro", afirma que "para o analista, o desconcerto é um estado necessário que longe de impossibilitar, talvez habilite o exercício de sua função ... uma posição a conquistar". Sinto grande afinidade com esses pontos de vista, embora suspeite que por caminhos diferentes. Como ressalta Green (1986) o aparelho psíquico descrito por Freud não é mais unanimidade no sentido de que o objeto desempenha um papel constitutivo do nascimento e funcionamento psíquico. São a experiência de viver (nascimento) e o desamparo primordial, as inevitáveis turbulências que o "vento da vida" provoca, que levam à procura do objeto e do amor. Na falha ou impossibilidade de um encontro com um outro psiquismo disponível para conter e sonhar, "gestar", as emoções e sensações despertadas pela cesura da vida, caímos nas agonias e terrores sem nome.

\footnotetext{
${ }^{1}$ Este trabalho foi apresentado em oficina sobre as plenárias no I Simpósio Bienal "O mesmo, o outro: Psicanálise em movimento", eixo "O analista desconcertado: mal estar e cínica” da Sociedade Brasileira de Psicanálise de São Paulo.

${ }^{2}$ Analista Didata da Sociedade Brasileira de Psicanálise de São Paulo.
} 
Parto da premissa de que Eros é inconcebível sem o objeto e, sendo o papel do objeto primário decisivo, não há experiência emocional desvinculada de uma relação. Os encontros entre analista e analisando na sessão analítica são impregnados pela emoção e/ou por sentimentos. Quando despojada dos conteúdos emocionais vivos, a relação torna-se "tecnológica", aproxima-se do inanimado, diminui a sua vitalidade, e nos deparamos com o negativo dos vínculos emocionais. Não por acaso Bion (1963) afirma que os elementos de psicanálise são funções da personalidade e que os objetos derivados deles, as associações e interpretações contem extensões nos domínios dos sentidos, dos mitos e da paixão.

Com a afirmativa de que para nascer um psiquismo é necessário outro psiquismo, capaz de pensamento onírico, Bion abriu o campo do intersubjetivo na relação analítica (não nos ocupamos mais apenas do intrapsíquico do paciente, como podemos observar na sessão descrita por Marcio, a partir de outro referencial teórico) e, do ponto de vista da técnica, coloca a pessoa do analista na sala de análise, com todas suas possibilidades e limitações, no sentido em que ele propõe o uso da visão binocular (consciente/inconsciente) pelo analista. Com isso, a presença da sua subjetividade adquire importância na sala de análise, possibilitando-lhe uma observação fina, a utilização de sua intuição analiticamente treinada e informada, e a captação do fato selecionado, a partir do qual poderá emergir um sentido ou significado ao até então não compreendido. A sessão passa a ser uma sucessão de movimentos resultantes da interação das duas mentes, desde o início do encontro. $\mathrm{O}$ foco do analista é o material para o qual ele tem evidência direta, isto é, a experiência emocional da dupla analítica no momento da sessão (“O”). Através da capacidade do analista para reverie, os seus pensamentos oníricos de vigília, capacidade negativa, a relação (qđ) e movimento $\mathrm{PS} \leftrightarrow \mathrm{D}$, o analista será capaz de perceber, conter, sonhar e, por exemplo, discernir a qualidade psíquica que o paciente pode não ser capaz de perceber e que provoca seu sofrimento, ou seja, a qualidade psíquica do conteúdo emocional vivido como um "estranho", o "outro em si" que precisa ser eliminado. Ao invés de focar principalmente nas ansiedades, defesas, cisões, retorno do reprimido ou fantasias inconscientes, embora elas se revelem na interação da dupla, o analista se volta para a possibilidade de fortalecimento ou mesmo desenvolvimento de capacidades e funções psíquicas do analisando, a partir de uma relação viva. Ambos se nutrem da experiência, em direção à expansão psíquica da dupla. $\mathrm{O}$ desenrolar desse processo vai depender das qualidades psíquicas do analista que serão comunicadas ao paciente através dos canais de comunicação afetivos, e dos seus inevitáveis 
impactos sobre a mente do paciente. Com isso, na cena analítica, o aqui e agora da relação vem para o primeiro plano, favorecendo um vínculo de intimidade, criatividade e, consequentemente, de abertura para o des-concerto.

2. Bion não se refere propriamente a uma estratégia técnica, mas a um estado de mente do analista na sala de análise. Na realidade, um estado de mente permanentemente "desconcertado". Para conhecer o outro, o analista necessita ter uma relação muito íntima consigo mesmo, só possível através de uma análise profunda, que o capacite também ao exercício de uma "disciplina" que leva em conta a variabilidade, a complexidade psíquica do ser humano e sua característica de sempre surpreender, tornando-lhe possível ir ao encontro do "outro" na sessão, sem memórias, sem desejos e, sem necessidade de compreensões, o acolhimento de "pensamentos selvagens". Mantendo a fé nos processos do inconsciente, o analista deve poder perder-se e, levantando os limites da atividade racional e da lógica que é própria da vigília habitual, desprender-se do amparo fornecido pelas estruturas teóricas e dos significados gratificantes "já conhecidos”, assim como das expectativas em relação ao outro. Oferecer uma escuta acolhedora e continente, contando mais com a própria capacidade negativa $^{3}$; continência suficiente para ficar no papel em que o analisando o colocar; certo estado de mente aberto à recepção de todos os objetos, quer sejam sentidos como bons ou maus, vindos do analisando (relação $+\overbrace{}^{\Uparrow}$ ); capacidade de função-alfa e movimentos $\mathrm{PS} \leftrightarrow \mathrm{D}$, do que com eventuais compreensões e atribuições de significados. Um analista presente de "corpo e alma" na sessão, capaz de transformar em presença a ausência irrepresentável, de transitar através de suas próprias cesuras entre as diferentes dimensões psíquicas ${ }^{4}$ sem se assustar (ou se deixar imobilizar caso se assuste) e transcender seus próprios vértices, sem perdê-los nem se perder de vista. A analise passa a ser então um processo sustentado no tempo pela presença do analista num setting capaz de oferecer estabilidade, continuidade e autenticidade, as condições fundamentais na constituição do sentido de si no processo de integração.

A direção em que se movimenta a investigação psicanalítica se sobrepõe aos espaços infinitos de Pascal e segue até alcançar os recessos profundos do Hades. Bion coloca o analista em contato com a angústia de conviver com o incerto, tolerar mistérios e dúvidas; com a percepção de que se pode estar cego, enganado nas próprias percepções, escolhas e decisões

\footnotetext{
${ }^{3}$ Conceito de Keats, citado por Bion (1992) que é a capacidade que um homem possui de estar em incertezas, mistérios e dúvidas, sem qualquer tentativa de alcançar fato e razão.

${ }^{4}$ A partir de Transformações, Bion utiliza-se do modelo de mente multidimensional.
} 
que acarretarão inevitáveis repercussões no futuro, mas sabendo também que essa limitada percepção é o único instrumento de que dispomos. A atmosfera emocional da sessão, as impressões do analista, o estado emocional da dupla analista-analisando, os próprios pensamentos oníricos são as únicas bússolas disponíveis. Esse estado de mente do analista em sessão ${ }^{5}$, de insaturação psíquica, torna-nos sensíveis ao que "não-é", ao que "não se encaixa", dificuldades, incômodos ou pré-sentimentos não assinalados ou mesmo nem percebidos pelo paciente, mas que uma vez captados pelo analista, podem funcionar como "sinalizações" que geralmente se apresentam na forma de intuição, imagens, lembranças oníricas, mitos, sonhos, sensações, etc. Para que os pensamentos oníricos sejam possíveis, torna-se condição necessária ao analista, a tolerância à dúvida e a um sentido de infinito, além de compaixão madura e respeito pelo paciente. Acolhimento amoroso e liberdade do objeto com paciência, tolerância e empatia formam a trama da rede continente a ser preenchida com os diferentes conteúdos emocionais $(+\not \hat{\jmath} \rightarrow \infty)$.

Outro capítulo dessa história seria a abordagem das condições psíquicas a serem privilegiadas em nosso vir-a-ser psicanalistas que nos habilitem a estar em estado psíquico de receptividade e atenção, com a possibilidade de viver uma mente em trânsito, sem portos seguros para atracar, e poder experimentar tornar-se a realidade juntamente com o paciente. Para tanto, é necessária ao analista a capacidade de ser parte e, ao mesmo tempo, estar separado da experiência, mantendo-se a função analítica. Penso que só podemos desenvolvela através de uma sólida formação e uma análise profunda, que alcance as cavernas mais profundas nos recessos de nossas mentes, às partes psicóticas $\leftrightarrow$ não-psicóticas e psicosomáticas $\leftrightarrow$ somato-psicóticas do próprio analista. Seria esse o domínio a que pertencem transformações de e em "O", que Bion ${ }^{6}$ tenta definir verbalmente como "realidade última", "a verdade absoluta", "a divindade", o seu conceito mais controverso, apenas parcialmente alcançado pelo entendimento racional. Estar em uníssono (at-one-ment) com "O” descreve a experiência de tornar-se "O”, expressão de ser (being) de uma pessoa. "O” de "Onthus, e de “Opus" (work in progress) ${ }^{7}$, trabalho em construção. Estar em uníssono com "O” depende da capacidade para integrar os estados mais primitivos da mente com as funções mentais superiores, através das quais as evoluções de "O" podem ser experenciadas ${ }^{8}$. Como sintetiza

\footnotetext{
${ }^{5}$ Mion C (2009)

${ }^{6}$ Bion, W (1970) Transformações.

${ }^{7}$ Chuster, A (2018) Encontro Bion em Ribeirão Preto.

${ }^{8}$ Willians, M (2010).
} 
lindamente Bollas9: "O self consciente está agora no lugar da criança que não sabe, que não pode pensar as experiências de ser, ao passo que é o self inconsciente que carrega a sabedoria da história do self e faz o trabalho profundo de processar os detalhes da experiência vivida por meio da sinfonia do pensamento inconsciente”.

Esses espaços infinitos são por demais assustadores. Algumas características da condição humana não se modificam independente da cultura, do mundo em que vivemos: o profundo desamparo em que nascemos, a consequente dependência do "outro" para sobrevivência física e para o nascimento psíquico, e a solidão inelutável. $\mathrm{O}$ fato é que nascemos completamente no escuro, e muito limitados para lidar com as circunstâncias traumáticas decorrentes da descoberta de estarmos vivos. Toda dor consciente vem do próprio fato de vivermos.

A mente humana não suporta o não-saber, o vazio. O medo do escuro é atávico: o homem primitivo, assim que descobriu o fogo ${ }^{10}$, passou a usar tochas para iluminar a escuridão da noite e das cavernas onde se refugiava, um medo que persiste como tal nas crianças pequenas. Nos adultos, porém, o medo do escuro se "sofisticaliza", digamos assim, e passa a ser expresso como medo das próprias "cavernas" onde busca refúgio, do desconhecido, do estranho que o habita, do "outro". As palavras e o pensamento surgem, como as tochas do homem primitivo, para lidar com a escuridão e a solidão que nos assustam. Logo percebemos que a linguagem verbal é muito ineficaz para expressar nossas emoções mais íntimas, nossas dores e perplexidades frente à vida. Uma forma encontrada pelo homem para dar sentido, significado e alguma previsibilidade a essas vivências, desde o princípio, são as fantasias, as narrativas, as estórias que contamos a nós mesmos, como por ex., quem é essa pessoa que está comigo, quem sou eu, quem é o "outro", o que é a vida, de onde vim, onde estou, para onde vou. E passamos a acreditar nelas. Assim adquirimos a ilusão do conhecimento consciente (-mente), e à medida que nos desenvolvemos, as estórias se tornam mais complexas, acrescentamos novos elementos, elas se tornam filosofia, medicina, psicologia, psicanálise, etc...

\footnotetext{
${ }^{9}$ Bollas, C (2009) A questão infinita.

${ }^{10}$ Segundo Luís da Câmara Cascudo, desde o Homem de Neandertal, conhecemos o fogo - Civilização e Cultura
} 
$\mathrm{Na}$ intimidade de nossos consultórios atualmente encontramos fundamentalismos de toda sorte, auto definições através do trabalho, individualidades empobrecidas, homens e mulheres com aspirações de serem eles mesmos, de adquirirem existência. A presença da subjetividade do analista na sala de análise aumenta as possibilidades de descrever o humano de tal forma que não se perca a esperança na possibilidade de encontros. Ser capaz de apreender as mais sutis nuances de comunicação inconsciente torna mais íntima e profunda a experiência da relação psicanalítica. A própria análise pessoal vai capacitar ao analista tolerar as experiências emocionais que envolvem o confronto com a incoerência, não compreensão, sentimentos de dúvida e até mesmo persecutoriedade. Não é fácil esse caminho, sempre na contramão da cultura. Viver um processo contínuo de aprendizado e desenvolvimento só é possível enquanto o analista mantiver sua paixão pela investigação e exploração das profundezas do inconsciente infinito e fé na psicanálise. 